\title{
Three-Phase AC-AC Hexagonal Chopper System with Heterodyne Modulation for Power Flow Control Enhancement
}

\author{
Peng Li, Yachao Wang, Grain Philip Adam Member IEEE, Derrick Holliday and Barry Williams
}

\begin{abstract}
This paper proposes a three-phase AC chopper system for the interconnection of various distributed generation (DG) farms or main utilities to enhance the active and reactive power flow control. The absence of large energy storage component in direct AC-AC converter makes the system footprint small and reliable. As the interface for different $\mathrm{AC}$ sources, the presented converter can be configured as star or delta. However, delta connection is preferred as it can trap the potential zero-sequence current and reduce the current rating of the switching devices. In this way, the proposed converter resembles the hexagonal chopper, and it offers an inherent degree of freedom for output voltage phase-shifting. Considering the scalability in high voltage applications, a new version of the hexagonal chopper with halfbridge cell modular multilevel structure is developed. The modular multilevel AC hexagonal chopper (M2AHC) is operated in quasi-2-level mode to suppress the electro-magnetic interference (EMI) caused by high voltage switching. Quasi-2level operation divides the voltage level transition into multi-steps, diminishing the voltage rising and falling rates $(d v / d t)$ in high voltage condition. Then, heterodyne modulation is adopted for the presented chopper system, supplying a new degree of freedom to decouple the phase and amplitude regulation. Based on this idea, system control strategy is developed in synchronous reference frame (SRF). Simulations and experimentations have confirmed the validity of the proposed approaches.
\end{abstract}

Index Terms - Three-phase, AC-AC conversion, DG, Utility, Hexagonal chopper, M2AHC, Quasi-two-level mode, Heterodyne modulation, SRF.

\section{NOMENCLATURE}

A Amplitude of output voltage for the hexagonal chopper system without heterodyne modulation

$\Delta \quad$ Phase-shift of output voltage for the hexagonal chopper system without heterodyne modulation

D Constant duty cycle for each phase

$\boldsymbol{n}$ Number of cells in each arm for the M2AHC

$\boldsymbol{n}_{\boldsymbol{u}} \quad$ Number of loaded cell capacitors in upper arm

$\boldsymbol{n}_{\boldsymbol{l}} \quad$ Number of loaded cell capacitors in lower arm

$\boldsymbol{\delta} \boldsymbol{t}$ Time step for quasi-2-level mode operation of M2AHC

$\boldsymbol{T}_{\boldsymbol{s}} \quad$ Switching period for the hexagonal chopper system

$\tau$ Duty cycle loss for quasi-2-level operation in M2AHC

$\boldsymbol{C}_{\boldsymbol{e}}$ Effective capacitor value in upper arm during certain switching state

$\boldsymbol{C}_{\boldsymbol{e}}$ Effective capacitor value in lower arm during certain switching state

$C_{c e l l}$ Cell capacitor value $\boldsymbol{i}_{\boldsymbol{h}}, \boldsymbol{i}_{\boldsymbol{i}}, \quad$ Upper arm current, lower arm current

$\boldsymbol{i}_{\boldsymbol{o}}, \boldsymbol{i}_{\text {cir }}$ Output current, circulating current

$\boldsymbol{A}_{\boldsymbol{H}} \quad$ Amplitude of output voltage for the hexagonal chopper system with heterodyne modulation

$\Delta_{\boldsymbol{H}} \quad$ Phase-shift of output voltage for the hexagonal chopper system with heterodyne modulation

\section{INTRODUCTION}

$\mathrm{O}$ ver the last two decades, penetrations of the distributed generation (DG) into traditional power system have been accelerated, and this has been encouraged by increasing popularity and development of smart grid. Nowadays, DG resources are being operated as part of large grids as well as in islanding mode called microgrid. Although microgrid concept is recently established, it has received great attention from academia and industry [1-5]. Solar and wind energy are being extensively integrated into grids by using power electronic converters, where DC-AC or back-to-back voltage source converter (VSC) is preferred due to its energy storage buffer that offers side-to-side decouple. Unlike the intermittent nature of renewable energy, conventional DGs such as synchronous generator arrays provide a stable power output with full control over frequency and voltage amplitude. Therefore, these DG resources are widely employed to stabilize the AC grid or microgrid with considerable amount of renewable energy incorporation. In AC power networks, the active and reactive power flow control is facilitated by using the droop method which slightly refines the voltage amplitude and phase [6-8]. However, this control range is limited by line impedance especially in long distance and meshed interconnections, where neither synchronous generator nor the VSC has the ability to force the power flow in specific branch beyond its terminal. In order to enhance the power flow control ability at reduced cost, direct AC-AC conversion can be employed as the interfacing converter between critical DG or utility buses.

In direct $\mathrm{AC}-\mathrm{AC}$ conversion area, matrix converter (MC) has attracted significant interest for its ability to regulate the frequency and phase without DC-link. Applications of MC in motor drive, power flow controller and wind turbine interface are investigated in [9-11]. However, numerous switching devices, complex modulation scheme combined with the high switching and conduction losses constrain the spread of MC. Additionally, the control and modulation of $\mathrm{MC}$ depend on the direct couple of input and output, leading to the increased possibility of system failure in fault conditions.

The vector switching converter (VeSC) has a reduced number of switches and simplified modulation compared to 
$\mathrm{MC}$ at the expense of incorporating multi-throw input voltages generated from the bulky phase shift transformer, which in turn increases the size and cost of the overall system [12].

AC chopper using bidirectional switches can be recognized as the particular case of $\mathrm{VeSC}$ with only one throw input voltage [13]. Generally, the AC chopper can only change the voltage amplitude with one throw input source and DC duty cycle modulation. In order to provide additional degree of freedom for voltage synthesis, the widely used heterodyne principle in communication can be transplanted into power converters. Heterodyne idea is based on trigonometric identities, where by inserting new frequency components into the modulating signal, new sinusoidal components and the relevant byproducts can be generated from the AC source. The literature $[14]$ and $[15,16]$ are special cases that using the heterodyne principle for $\mathrm{VeSC}$ and $\mathrm{AC}$ chopper respectively. However, $3^{\text {rd }}$ order harmonic current will be drawn from the input source in these schemes.

For high and medium wind turbine interfacing applications, the Hexverter originated from the back-to-back modular multilevel converter (MMC) by omitting the DC-link is presented in [17]. However, weak decouple still exists since large DC cell capacitor and H-bridge cell are employed for voltage synthesis and reverse blocking. Consequently, the branch current comprises of large DC component to facilitate power transfer between two $\mathrm{AC}$ side and $\mathrm{AC}$ components associated with frequencies of both $\mathrm{AC}$ sides and their interactions. In summary, the Hexverter is suitable for interfacing of future multi-megawatt variable speed windturbine generators due to decoupling feature inherent from the use of the DC capacitors. However, in another side, the incorporation of large DC capacitors makes it less competitive as power flow controller between two synchronous $\mathrm{AC}$ grids.

This paper presents a three-phase hexagonal AC chopper as interfacing converter for interconnection between DG farms or utilities, and specifically, it can be used as AC grid voltage regulator, flexible AC transmission system (FACTS) devices, off-line programmable AC voltage source, etc. The hexagonal configuration of the $\mathrm{AC}$ chopper forms a delta connection of three phases, where zero-sequence current can be trapped. In attempt to extend the voltage and power rating, the hexagonal chopper has been derived into modular multilevel AC hexagonal chopper (M2AHC). Since the overall system is direct AC-AC conversion, the cell capacitors of the M2AHC are $\mathrm{AC}$ type with small value. Accordingly, the arm inductance is also very small and sometimes even can be merged into the stray inductance. The quasi-2-level operation is investigated on the M2AHC to offer further reduction of cell capacitance, small voltage transient step (less EMI) and consistent system control with real-2-level chopper. Heterodyne principle is employed to synthesize a phaseshifted output voltage from the input by the cancellation of the byproducts between phases. Based on this idea, a multi-layer multi-loop system control scheme has been developed in SRF for the hexagonal chopper. The hexagonal chopper can be organized as back-to-back system if each AC network has this chopper in the terminal, doubling the control flexibility and adapting the voltage amplitude (since AC chopper is a stepdown converter). However, a common step-up transformer is assumed at converter output in this paper to allow the concentration on a single converter unit. The rest of this paper is organized as follows: section II gives the principle of hexagonal chopper and its scalable version M2AHC with quasi-2-level operation; section III describes the heterodyne modulation in SRF based on the system model of the chopper system; then, simulation and experiment results have been demonstrated in section IV to verify the feasibility of the proposed converter and its control scheme; finally, some conclusions have been highlighted in section $\mathrm{V}$.

\section{Proposed Three-Phase HeXagonal Chopper SYSTEM}

In this section, operation principles of proposed hexagonal chopper and its extension - M2AHC are analyzed. The two versions of chopper system are equivalent from system point of view and have similar relationship as between 2-level VSC and MMC in DC-AC applications.

\section{A. Performance Analysis of Hexagonal Chopper}

The schematic of proposed three-phase hexagonal chopper is depicted in Fig. 1. Six groups of series-connected insulated gate bipolar transistor (IGBT) as the bidirectional switches are used to form a hexagonal ring. The switches are denoted as $S_{x y}$ ( $x=a, b, c$ stand for the chopper phases; and $y=1,2$ stand for upper and lower arms, which are distinguished by red and blue in Fig. 1). The two IGBTs in each bidirectional switch are driven by the same signal, while the upper and lower switches of one phase are complementarily triggered in pulse width modulation (PWM) scheme. $\{A, B, C\}$ and $\left\{A_{o}, B_{o}, C_{o}\right\}$ are three input and output terminals respectively. It is observed that the risk of resonance between line filters when zerosequence current is drawn can be avoided due to solid connection of capacitor terminals compared to three-wire star connection.

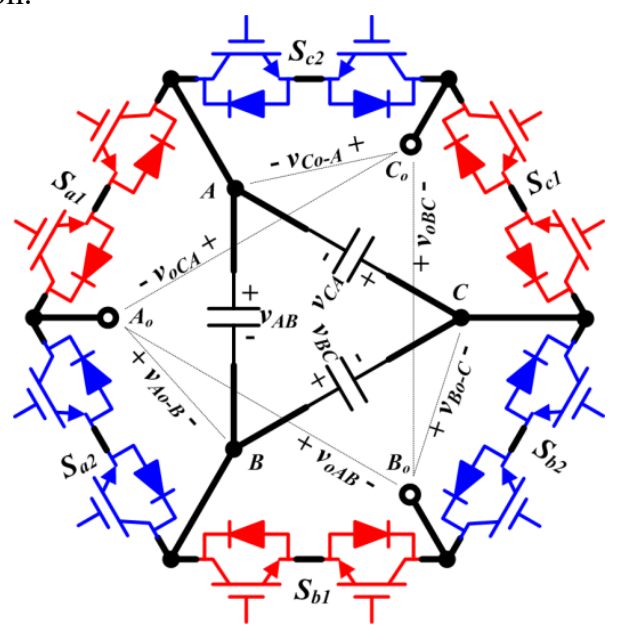

Fig. 1. Proposed three-phase hexagonal chopper (without filter).

In Fig. 1, each phase works as a buck-type AC chopper, and the directly generated voltages are denoted as $\left\{v_{A o-B}, v_{B o-C}\right.$, $\left.v_{C o-A}\right\} .\left\{d_{a}, d_{b}, d_{c}\right\}$ are the duty cycles of the upper switches. $\left\{v_{A B}, v_{B C}, v_{C A}\right\}$ are the input line voltages. Notice that the output voltages $\left\{v_{A o-B}, v_{B o-C}, v_{C o-A}\right\}$ can be related to input voltages $\left\{v_{A B}, v_{B C}, v_{C A}\right\}$ by using duty cycles of the upper switches as: $v_{A o-B}=d_{a} v_{A B}, \quad v_{B o-C}=d_{b} v_{B C}$ and $v_{C o-A}=d_{c} v_{C A}$. Accordingly, the output line voltages $\left\{v_{o A B}, v_{o B C}, v_{o C A}\right\}$ can be achieved by (1). 


$$
\left\{\begin{array}{l}
v_{o A B}=v_{A o-B}-v_{B o-C}+v_{B C}=v_{A B} \cdot d_{a}+v_{B C} \cdot\left(1-d_{b}\right) \\
v_{o B C}=v_{B o-C}-v_{C o-A}+v_{C A}=v_{B C} \cdot d_{b}+v_{C A} \cdot\left(1-d_{c}\right) \\
v_{o C A}=v_{C o-A}-v_{A o-B}+v_{A B}=v_{C A} \cdot d_{c}+v_{A B} \cdot\left(1-d_{a}\right)
\end{array}\right.
$$

In normal operation, the duty cycles of three phases are equal with pure DC component denoted as $D$. Considering the sinusoidal input voltage in (2), where $v_{m}$ and $\omega$ are the amplitude and angular frequency of the input voltage respectively, (1) can be concretized into (3) with the definitions in (4).

$$
\begin{aligned}
& \left\{\begin{array}{l}
v_{A B}=v_{m} \cdot \cos \omega t \\
v_{B C}=v_{m} \cdot \cos (\omega t-2 \pi / 3) \\
v_{C A}=v_{m} \cdot \cos (\omega t+2 \pi / 3)
\end{array}\right. \\
& \left\{\begin{array}{l}
v_{O A B}=A \cdot v_{m} \cdot \cos (\omega t+\Delta) \\
v_{o B C}=A \cdot v_{m} \cdot \cos (\omega t+\Delta-2 \pi / 3) \\
v_{o C A}=A \cdot v_{m} \cdot \cos (\omega t+\Delta+2 \pi / 3)
\end{array}\right. \\
& \left\{\begin{array}{l}
A=\sqrt{3 D^{2}-3 D+1} \\
\Delta=-\cos ^{-1}\left(\frac{3 D-1}{2 A}\right)
\end{array}\right.
\end{aligned}
$$

Fig. 2 shows the plot of $A$ and $\Delta$ (in degree) varying with $D$. It can be found that the hexagonal chopper works similarly as a Zig-Zag transformer as it offers the ability of output voltage phase-shifting i.e. the flexibility for power flow control, which is an additional superiority of the proposed configuration over the star connection where only amplitude can be adjusted.

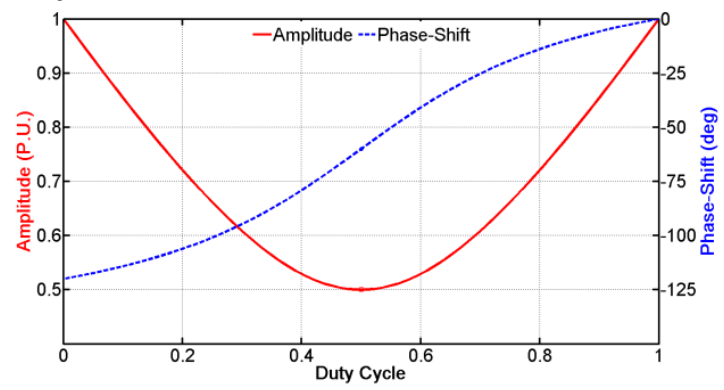

Fig. 2. Amplitude and phase of output line voltage vary with DC duty cycle for the hexagonal chopper.

From Fig. 2, when $D=0.5$ is the initial operation point, the phase-shift range can be maximum and bidirectional. However, the phase regulation will also change the amplitude (minimum 0.5 ) due to the envelope of input voltage in the constant duty cycle mode and the lack of decoupling between amplitude and phase control. This issue is to be investigated in later section to avoid the use of on-load tap changer (OLTC) or extra converter for voltage amplitude recovering (decoupling).

\section{B. M2AHC with Quasi-2-Level Operation Mode}

In high and medium voltage applications, the presented hexagonal chopper requires series connection of bidirectional switches to operate in typical two-level mode. In order to reduce the EMI generated from high frequency switching of high voltage levels and avoid the uneven dynamic voltage sharing amongst the series connected semiconductor devices (low reliability), the $\mathrm{M} 2 \mathrm{AHC}$ operating in quasi-2-level mode has been developed as depicted in Fig. 3, where it replaces the switches of Fig. 1 by chain link of half-bridge cells and inductors in each arm to enable scalability to high power and high voltage applications. The cell capacitors in the proposed M2AHC only sustain pure AC voltage, allowing the use of small AC capacitors instead of large DC ones as presented in Hexverter [17]. Naturally, arm inductors used to limit the inrush current of the inner hexagonal ring during transient voltage mismatch between input voltage and sum of the nonbypassed cell capacitor voltages can be largely reduced compared with MMC or Hexverter. Quasi-2-level operation mode interpreted in Fig. 4 is adopted to minimize the $d v / d t$ on equipment that may be connected to its output. It is observed that the proposed quasi-2-level operation divides voltage level transition into multiple steps without significant compromise to duty cycle information. It facilitates orderly transition of output voltage from level ' 0 ' to level ' 1 ' (and vice versa) through intermediate voltage levels (artificially created). These intermediate voltage levels enable sequential switching of the MMC cells of the upper and lower arms in and out of the power path. In this way, the voltage gradient $(d v / d t)$ during switching transitions is greatly reduced, hence, enhances the system reliability [18].

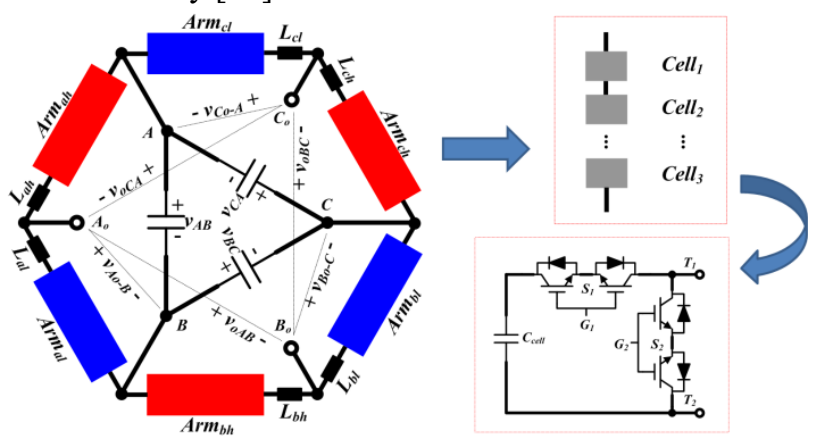

Fig. 3. Proposed M2AHC with its arm and cell structures.



(a)

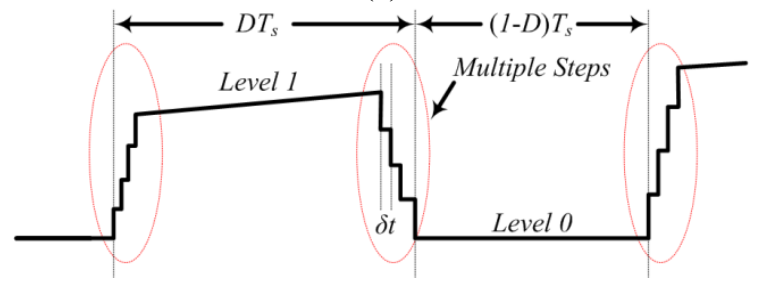

(b)

Fig. 4. Comparison between (a) real-2-level and (b) quasi-2-level modes for AC chopper system.

The above discussions have shown that the proposed $\mathrm{M} 2 \mathrm{AHC}$ is completely different from Hexverter [17], although topologically they look similar. The main differences are summarized as follows:

a) The M2AHC using half-bridge cell (with bidirectional switches) contains no large energy storage component; because the cell capacitor voltages are pure AC (arm inductances are also very small and may be merged into stray 
inductances in incompact design). However, Hexverter uses full-bridge cell (with unidirectional switches) and incorporates large DC capacitor in each cell [19].

b) The presented converter operates in quasi-2-level mode, while the Hexverter works in typical multilevel mode.

c) The presented converter acts as an AC chopper from the system point of view, where duty cycle is the control input. In another hand, the Hexverter is derived from the back-to-back $\mathrm{MMC}$ and can be viewed as an indirect AC-AC system.

d) The arm current in $\mathrm{M} 2 \mathrm{AHC}$ is discontinuous and transits between zero and load current by multi-steps $(d i / d t$ is limited), while Hexverter (also MMC) holds continuous arm current. Lower conduction losses are expected in M2AHC.

e) Normally, only fundamental and high frequency currents flow in the $\mathrm{M} 2 \mathrm{AHC}$ arm. However, circulating current of $\mathrm{MMC}$ or Hexverter contains $\mathrm{DC}$ and $2^{\text {nd }}$ order components.

It is worth mentioning that the use of bidirectional switches in the chopper system facilities the reverse blocking capability for half-bridge cell configuration under fault conditions.

Design issues for M2AHC with quasi-2-level operation are investigated in following parts.

\section{1) Parameter Selection}

Input $C$-filter and output $L C$-filter are designed according to the well-established routines discussed in [20], which will not be covered here.

Similar as conventional MMC, each arm of the M2AHC must be able to block the peak of the input voltage. This means each phase of M2AHC must have $2 n$ cells ( $n$ cells per arm). During normal operation, the total number of series cells in power path from the upper and lower arms at any instant must be equal to $n$. This means $n_{u}+n_{l}=n$, where $n_{u}$ and $n_{l}$ are the instantaneous number of cells selected from the upper and lower arms. Moreover, it must be noticed that when $n_{u}=0$ $\left(n_{l}=n\right)$ and $n_{l}=0\left(n_{u}=n\right)$, the output poles $\left(A_{o}, B_{o}\right.$ and $\left.C_{o}\right)$ of the $\mathrm{M} 2 \mathrm{AHC}$ are connected to level ' 1 ' and level ' 0 ' of their individual phases respectively. Thus, the maximum voltage stress per cell is limited to $V_{m} / n$, where $V_{m}$ is input voltage peak and $n$ is cell numbers per arm.

Fig. 4(b) shows that the quasi-2-level operation for M2AHC is achieved by modifications introduced to the typical two-level duty cycle in Fig. 4(a), hence, the total time spend on the intermediate voltage levels limits the maximum fundamental output voltage. This drawback can be minimized by making the dwell time at each intermediate voltage level sufficiently small just to ensure smooth transition of the output voltage between level ' 0 ' and ' 1 '. In this way, the system level consistency between $\mathrm{M} 2 \mathrm{AHC}$ and the 2-level hexagonal chopper can be maintained. From Fig. 4(b), the duty cycle loss can be calculated by (5), where $T_{s}$ is the switching period and $\delta t$ is the duration for each step.

$$
\tau=(n-1) \cdot \delta t / T_{s}
$$

The step number is constrained by the duty cycle loss. Considering one typical application, where $1 \mathrm{kHz}$ switching frequency and IGBT module with switching delay of about $5 \mu$ s (Infineon FZ1500R33HL3) are employed, the step duration $\delta t$ can be chosen as $10 \mu \mathrm{s}$. In this case, if maximum tolerance of duty cycle loss is $8 \%$, at most 9 cells per arm (10level waveform in the transition) are allowable according to (5). The existence of this limit is reasonable because the purpose of $\mathrm{M} 2 \mathrm{AHC}$ is not to track references as in conventional MMC.



(a)



(c)

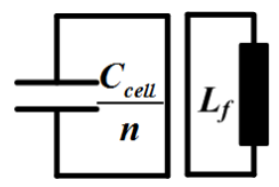

(b)



(d)
Fig. 5. Equivalent model of M2AHC: (a) quasi-2-level transient model; (b) power loop in steady-state; (c) Arm current model; (d) inner branch model.

For the design of $\mathrm{M} 2 \mathrm{AHC}$, another difference compared to MMC, Hexverter or quasi-2-level DC-AC converter [18] where DC-link decouple or weak decouple exists is the calculation of cell capacitance and arm inductance.

In the conventional converters, DC cell capacitor is chosen based on switching ripple demand, while the $\mathrm{M} 2 \mathrm{AHC}$ is pure AC system allowing the use of AC capacitors. Considering the simplified transient model for the M2AHC in Fig. 5(a), $C_{e h}$ and $C_{e l}$ are the equivalent capacitances of the non-bypassed cells in upper and lower arms during quasi-2-level transition. All $n$ cell capacitors in each arm are either clamped to input voltage or bypassed after transition as in Fig. 5(b). $C_{\text {cell }}$ and $L_{f}$ are the cell capacitance and output filter inductance. State equation can be established as (6), from which equivalent resonant frequency $f_{r}$ between $C_{e h} / / C_{e l}$ and $L_{f}$ must fall into the interval between the fundamental frequency $f_{o}$ and switching frequency $f_{s w}$ as (7). If $f_{r}$ is smaller than $f_{o}$ (large $C_{c e l l}$ ), cell capacitor voltages cannot follow up the trend of output voltage; while if $f_{r}$ is larger than $f_{s w}$ (small $C_{c e l l}$ ), the high frequency oscillation will disturb the step voltage during transition. Practically, geometrical mean value of the normalized frequencies are suggested as the resonant frequency $f_{r 0}$ of $C_{c e l l}$ and $L_{f}$ as shown in (8). Notice that cell capacitor voltage in $\mathrm{M} 2 \mathrm{AHC}$ is pure AC, while quasi-2-level operation of conventional MMC still uses DC cell capacitor to keep its voltage constant. In this sense, the presented M2AHC is able to use smaller cell capacitors than [18] under same operating condition.

$$
\left\{\begin{array}{l}
L_{f}\left(C_{e h} / / C_{e l}\right) \cdot \frac{d^{2} v_{c}}{d t^{2}}+k \cdot v_{c}=v_{i}-v_{o} \\
\frac{n}{n-1} \geq \frac{C_{e h} / / C_{e l}}{C_{c e l l}} \geq\left[\frac{1}{\operatorname{floor}(n / 2)}+\frac{1}{\operatorname{ceil}(n / 2)}\right]
\end{array}\right.
$$




$$
\begin{aligned}
& \left\{\begin{array}{l}
1 /\left(2 \pi \sqrt{\frac{n}{n-1} C_{\text {cell }} L_{f}}\right)>f_{o} \\
1 /\left(2 \pi \sqrt{\left[\frac{1}{\text { floor }(n / 2)}+\frac{1}{\operatorname{ceil}(n / 2)}\right] C_{\text {cell }} L_{f}}\right)<f_{\text {sw }}
\end{array}\right. \\
& \left\{\begin{array}{l}
f_{r 0}=1 /\left(2 \pi \cdot \sqrt{L_{f} C_{\text {cell }}}\right)=\sqrt{N \cdot f_{o} \cdot f_{\text {sw }}} \\
N=\sqrt{\frac{n}{n-1} \cdot\left[\frac{1}{\text { floor }(n / 2)}+\frac{1}{\text { ceil }(n / 2)}\right]}
\end{array}\right.
\end{aligned}
$$

For typical 2-level hexagonal chopper, the load current alternatively flows out of (into) one switch and its complement according to the duty cycle. Hence, pure fundamental current (in phase with load current) is carried by each arm. For M2AHC, neglecting the quasi-2-level process, considering Fig. 5(c) and constant duty cycle $D$, the arm currents are expressed as (9), which is in accordance to 2-level chopper. Practically, small phase-shift will be introduced to upper and lower arm currents by the quasi-2-level transition delay. However, this will have no influence on the system performance since (10) (Kirchhoff's Law) always holds ( $i_{c i r}$ is the circulating current in the hexagonal ring).

$$
\begin{aligned}
& \left\{\begin{array}{l}
i_{h}=D \cdot i_{o} \\
i_{l}=-(1-D) \cdot i_{o}
\end{array}\right. \\
& \left\{\begin{array}{l}
i_{o}=i_{h}-i_{l} \\
i_{\text {cir }}=\left(i_{h}+i_{l}\right) / 2
\end{array}\right.
\end{aligned}
$$

From Fig. 5(d), the arm inductance is evaluated. As analyzed above, the arm current of M2AHC contains only fundamental component. Since $n$ cell capacitors are series connected at any instance, the inner branch characteristic impedance $\zeta$ can be obtained in (11). In order to damp the high frequency inrush current (due to cell capacitor voltage error) properly and reduce the fundamental voltage drop on arm inductance, trade-off must be made based on the output power level and inner ripple current demand (current ratings for power devices) when selecting the characteristic impedance $\zeta$, and $L_{\text {arm }}$ can be achieved accordingly.

$$
\zeta=\sqrt{2 n L_{\text {arm }} / C_{\text {cell }}}
$$

\section{2) Voltage Balancing Strategy}

The cell capacitor voltage balancing strategy is explained using an illustrative example with two cells per arm in Fig. 6(a). By detecting the load current direction and voltage differences between relevant cell capacitors, the appropriate redundant switching states can be assigned to compensate voltage errors [21]. Similar with conventional MMC, output voltage of M2AHC with two cells per arm contains one intermediate voltage level which can be synthesized by multiple switching combinations (redundant switch states). Modulation strategy for three-level M2AHC is interpreted as follows:

1) The duty cycle command is transferred to the converter denoted as $R e f_{1}$ in Fig. 6(c). A discounted reference signal $\operatorname{Ref}_{2}$ is calculated from $\operatorname{Ref}_{1}$ and the subtraction between them determines the duration of the intermediate step, which is much smaller compared to the original duty cycle.

\begin{tabular}{|c|c|c|c|}
\hline$V_{\mathrm{H} 1-}-V_{\mathrm{H} 2}$ & $V_{\mathrm{L} 1}-V_{\mathrm{L} 2}$ & $i_{o}$ & $\begin{array}{c}\text { Switching } \\
\text { States }\end{array}$ \\
\hline+ & + & + & 01101001 \\
\hline+ & - & + & 01100110 \\
\hline- & + & + & 10011001 \\
\hline- & - & + & 10010110 \\
\hline+ & + & - & 10010110 \\
\hline+ & - & - & 10011001 \\
\hline- & + & - & 01100110 \\
\hline- & - & - & 01101001 \\
\hline
\end{tabular}

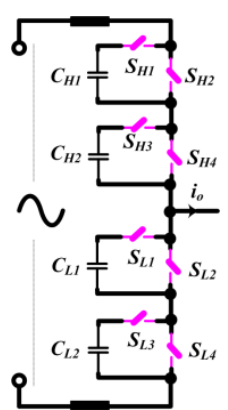

(a)

\begin{tabular}{|c|c|c|c|c|c|c|c|c|}
\hline$V_{o}$ & $S_{H 1}$ & $S_{H 2}$ & $S_{H 3}$ & $S_{H 4}$ & $S_{L 1}$ & $S_{L 2}$ & $S_{L 3}$ & $S_{L 4}$ \\
\hline Level 1 & 0 & 1 & 0 & 1 & 1 & 0 & 1 & 0 \\
\hline \multirow{4}{*}{$\begin{array}{c}\text { Intermed- } \\
\text { iate Step }\end{array}$} & 1 & 0 & 0 & 1 & 0 & 1 & 1 & 0 \\
\cline { 2 - 10 } & 1 & 0 & 0 & 1 & 1 & 0 & 0 & 1 \\
\cline { 2 - 9 } & 0 & 1 & 1 & 0 & 1 & 0 & 0 & 1 \\
\cline { 2 - 9 } & 0 & 1 & 1 & 0 & 0 & 1 & 1 & 0 \\
\hline Level 0 & 1 & 0 & 1 & 0 & 0 & 1 & 0 & 1 \\
\hline
\end{tabular}

(b)

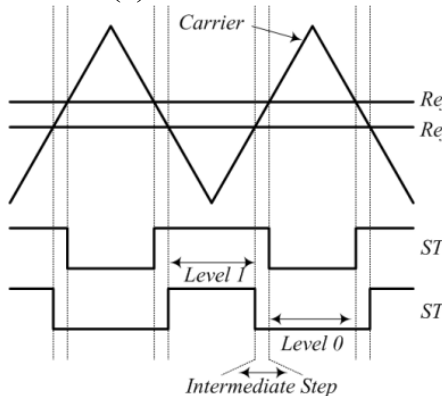

(c) (d)
Fig. 6. Interpretation of the modulation for three-level MMC based hexagonal chopper: (a). configuration for one phase; (b). output voltage level and relevant switching states; (c). modulating signal to define the voltage output states; (d). voltage balancing strategy.

2) According to the difference between $\operatorname{Ref}_{1}$ and $\operatorname{Ref}_{2}$. The pulse signals $S T_{1}$ and $S T_{2}$ are obtained. In Fig. 6(b), if $S T_{1} \& \&$ $S T_{2}=1$, the two upper cells both generate 'zero' and output voltage is 'Level 1'; while if $S T_{1} \| S T_{2}=0$, two upper cells both give 'one', and output voltage is 'Level 0 '. All remaining states belong to intermediate voltage level used for voltage balancing by taking into account the arm or output current direction.

3) The redundant switching states for intermediate voltage level of the output voltage are assigned according to the output current direction and cell capacitor voltage difference in Fig. 6(d). For example, assuming that load current flows out of the converter, if voltage on $C_{H 1}$ is larger than that on $C_{H 2}$, the upper arm switching state should be set to '0110'; while if $V_{L I}$ is smaller than $V_{L 2}$, the lower arm should have a switching state of ' 1001 '. In this analogy, remaining states can be deduced.

Larger number cells M2AHC with quasi-2-level mode can be modulated similarly to the illustrative example above but with more sophisticated software overhead for cell capacitor voltage sorting and switching state selection.

Since the quasi-2-level mode M2AHC introduces minor modifications to the duty cycle of the two-level AC chopper in Fig. 1 to allow generation of intermediate voltage states, the system level equivalence between them can be concluded. Therefore, hexagonal chopper and M2AHC share the same control scheme from system point of view similar as 2-level $\mathrm{VSC}$ and MMC in DC-AC applications.

\section{HETERODYNE MOdULATION AND SYSTEM CONTROL}

The problem of the hexagonal chopper system so far can be examined from Fig. 2, where the phase regulation will simultaneously cause amplitude changes if duty cycles are 
constrained to be equal DC value (as assumed above). This situation is the same with that in Zig-Zag transformer, where OLTC is employed to further adjust the amplitude. Besides, the minimum value of amplitude is 0.5 , which means the voltage control range is limited. In order to overcome these drawbacks and improve the flexibility of the presented system, new degree of freedom for voltage synthesis has been developed by exploiting the heterodyne principle, which is clarified by the trigonometric identity in (12).

$$
\left\{\begin{array}{c}
\cos \alpha \cdot \cos \beta=[\cos (\alpha-\beta)+\cos (\alpha+\beta)] / 2 \\
\cos \omega t \cdot \cos (-2 \omega t+\varphi)=\frac{1}{2}[\cos (\omega t-\varphi)+\cos (3 \omega t-\varphi)] \\
\cos \left(\omega t-\frac{2 \pi}{3}\right) \cdot \cos \left(-2 \omega t+\varphi-\frac{2 \pi}{3}\right)=\frac{1}{2}\left[\cos \left(\omega t-\varphi-\frac{2 \pi}{3}\right)+\cos (3 \omega t-\varphi)\right] \\
\cos \left(\omega t+\frac{2 \pi}{3}\right) \cdot \cos \left(-2 \omega t+\varphi+\frac{2 \pi}{3}\right)=\frac{1}{2}\left[\cos \left(\omega t-\varphi+\frac{2 \pi}{3}\right)+\cos (3 \omega t-\varphi)\right]
\end{array}\right.
$$

Considering the fundamental input line voltage (positive sequence), the $2^{\text {nd }}$ order harmonic component in negative sequence is inserted into the modulating signal to generate a phase-shifted positive sequence fundamental together with the by-product of $3^{\text {rd }}$ order harmonic component (zero sequence) that cannot propagate in three-phase system. This derivation in (13) is equivalent to the even harmonic modulation (EHM) presented in [15], which is a special case of the heterodyne method.

Practically, the three-phase modulating signals are chosen as (14) with the range between 0 and 1. From (1), (2), (3), (13) and (14), by the cancellation of the zero-sequence components, the output phase voltage denoted as $\left\{v_{o p A}, v_{o p B}\right.$, $\left.v_{o p C}\right\}$ can be calculated by (15) and (16).

$$
\begin{gathered}
\left\{\begin{array}{l}
d_{a}=k_{0}+k_{2} \cos (-2 \omega t+\varphi) \\
d_{b}=k_{0}+k_{2} \cos (-2 \omega t+\varphi-2 \pi / 3), \text { with }\left\{\begin{array}{l}
\left|k_{0}\right|+\left|k_{2}\right| \leq 1 \\
0 \leq k_{0} \leq 1
\end{array}\right.
\end{array}\right. \\
\left\{\begin{array}{l}
v_{c o p}=k_{0}+k_{2} \cos (-2 \omega t+\varphi+2 \pi / 3) \\
v_{o p B}=v_{m} \cdot\left[A_{d} \cdot \cos \omega t-A_{q} \cdot \sin \omega t\right] \\
v_{o p C}=v_{m} \cdot\left[A_{d} \cdot \cos (\omega t-2 \pi / 3)-A_{q} \cdot \sin (\omega t-2 \pi / 3)\right]
\end{array}\right. \\
\left\{\begin{array}{l}
A_{d}=\left(2 k_{0}-1+k_{2} \cos \varphi\right) / 2 \\
A_{q}=-\left(1+\sqrt{3} k_{2} \sin \varphi\right) / 2 \sqrt{3}
\end{array}\right.
\end{gathered}
$$

From above analysis, the introduced degree of freedom can regulate the direct component of input voltage and generate a new controllable quadrature component, by which the phase control can be achieved independent of amplitude regulation. Notice that $k_{0}$ is practically suggested to be around 0.5 to guarantee a maximum range for $2^{\text {nd }}$ order modulating signals.

Check Fig. 2, the maximum and bidirectional power flow control range can be achieved around the initial point (zero power flow point) at half duty cycle. This point has an inherent $-60^{\circ}$ phase shift and 0.5 amplitude gain compared with input $\mathrm{AC}$ voltage due to the delta connection of three phases. This voltage adaption issue can be thoroughly fixed by the back-to-back configuration if each AC network is equipped with the presented chopper system. However, a 1:2 interfacing transformer with $60^{\circ}$ leading phase shift is assumed in the following parts to adapt the converter output voltage to the grid. This simplification allows the concentration on the performance analysis for a single converter unit.

\section{A. The Arm Current under Heterodyne Modulation}

With the presented heterodyne method, the arm currents for hexagonal chopper and M2AHC are reevaluated. From (9) and (14), the arm current (phase A) is shown in (17), where $I_{m}$ is peak value of load current and $\beta$ is power factor angle. In further, the circulating current is calculated in (18).

$$
\begin{gathered}
\left\{\begin{array}{l}
i_{a h}=\left[k_{0}+k_{2} \cos (-2 \omega t+\varphi)\right] \cdot I_{m} \cos (\omega t+\beta) \\
i_{a l}=\left[k_{0}-1+k_{2} \cos (-2 \omega t+\varphi)\right] \cdot I_{m} \cos (\omega t+\beta)
\end{array}\right. \\
i_{c i r}=\left(k_{0}-\frac{1}{2}\right) I_{m} \cos (\omega t+\beta)+\frac{k_{2} I_{m}}{2}[\cos (\omega t-\varphi-\beta)+\cos (3 \omega t-\varphi+\beta)](18
\end{gathered}
$$

In (18), the circulating current of the presented hexagonal chopper and M2AHC contains fundamental and $3^{\text {rd }}$ order zerosequence components when heterodyne modulation is employed. In this way, the line currents in input and output terminals are only in fundamental (high frequency ripples can be easily filtered out). However, if the chopper system is configured as star, neutral line must be used as power path for the $3^{\text {rd }}$ order current which will be drawn from the input current [15], otherwise, resonance on the input filter will take place. This is another advantage of using delta connected hexagonal chopper. Notice that for the M2AHC, the arm current is still discontinuous and with a width-variant chopped shape after the insertion of AC components in modulating signals. Since the fact that $n$ cell capacitors are activated at any instance is always true for $\mathrm{M} 2 \mathrm{AHC}$, the cell capacitor voltage will not be influenced by heterodyne modulation.

\section{B. Power Flow Control Range with Heterodyne Method}

From (16), the output line voltage magnitude and angle can be expressed as (19) after using the heterodyne method. Compared with (4) and Fig. 2, new degree of freedom for voltage synthesis and power flow control is addressed by the heterodyne modulation. Practically, the voltage variation range of the interfacing converter (hexagonal chopper in this paper) is very small in order to maintain the stability of the parallel AC system, and this narrow range is sufficient for power flow control (this is different from the series compensation device with fractional power rating, where the converter operational point varies a lot $[22,23])$. Therefore, the output voltage amplitude gain for the presented hexagonal chopper is considered to be controlled constantly in the first step. In this case, with the fixed $k_{0}$, the relationship between $k_{2}$ and $\varphi$ is also fixed. Thus, the relevant phase-shift range can be obtained by evaluating (19). However, since it is difficult to get the analytic solution for the transcendental equations, some graphical results are investigated considering the range of $k_{0}$, $k_{2}$ in (14).

In Fig. 7(a), the voltage amplitude is controlled to be 0.5, and the output voltage phase-shift ranges of three typical cases $\left(k_{0}=0.55, k_{0}=0.5, k_{0}=0.45\right)$ are plotted. It is observed that the inserted $2^{\text {nd }}$ order modulating signal is capable of decoupling the amplitude regulation and phase control. When amplitude is fixed, a sufficient phase-shift range around the initial point ($60^{\circ}$ ) can be achieved for power flow control. Similar conclusion is drawn from Fig. 7(b) when amplitude gain is set 
to be 0.55 . In Fig. 7(c), it is noticed that the amplitude can be maintained as 0.45 which is lower than the valley value of 0.5 without heterodyne method (Fig. 2), and the output voltage phase-shift can also be implemented.

$\left\{\begin{array}{l}A_{H}=\sqrt{\frac{1+3\left(2 k_{0}-1\right)^{2}+3 k_{2}^{2}}{4}+\frac{3\left(2 k_{0}-1\right) k_{2} \cos \varphi+\sqrt{3} k_{2} \sin \varphi}{2}} \\ \Delta_{H}=-\cos ^{-1}\left[\frac{\sqrt{3}\left(2 k_{0}-1\right)+\sqrt{3} k_{2} \cos \varphi}{2 A_{H}}\right]+30^{\circ}\end{array}\right.$

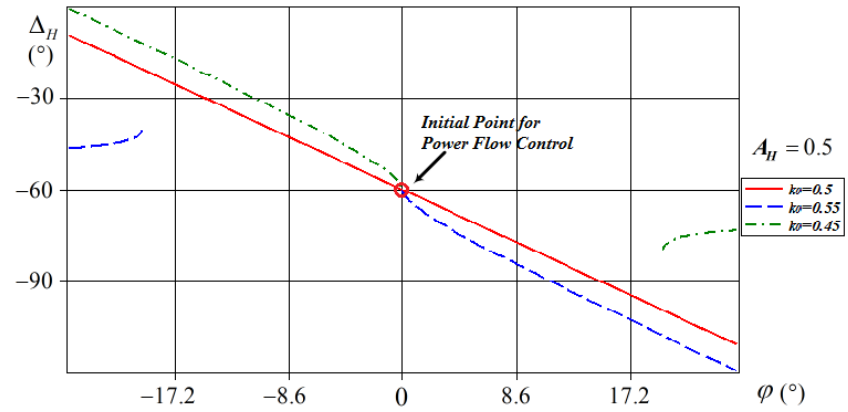

(a)

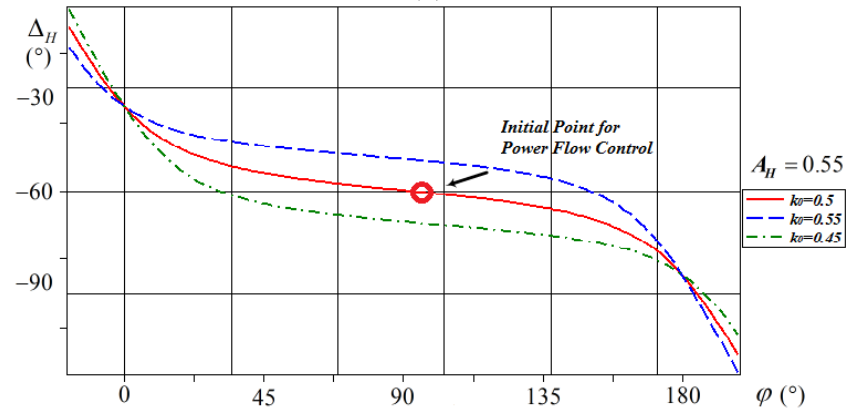

(b)

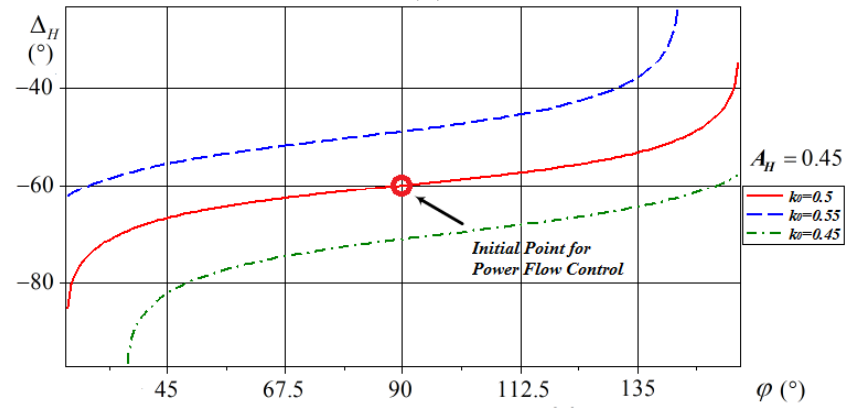

(c)

Fig. 7. Phase-shift range with heterodyne modulation: (a) $A_{H}=0.5$; (b) $A_{H}=0.55$; (c) $A_{H}=0.45$.

Typically, if $k_{0} \approx 0.5\left(0 \leq k_{2} \leq 0.5\right)$, output bus voltage $v_{b} \approx v_{i}$ by using a 1:2 transformer with $60^{\circ}$ leading for voltage adaption (this adaption transformer can be avoided by back-to-back structure but not considered in this paper as stated above) and bus phase difference $\delta=2^{\circ}$, the power flow output of proposed hexagonal chopper system can be obtained by (20) if inductive impedance dominates [1]. Accordingly, Fig. 8 shows the theoretical power flow control range of the presented system when using heterodyne modulation and normalized by (21).

$$
\left\{\begin{array}{l}
P=\frac{2 A_{H} v_{i} v_{b} \sin \left(\delta+\Delta_{H}+\pi / 3\right)}{X} \\
Q=\frac{2 A_{H} v_{i}\left[2 A_{H} v_{i}-v_{b} \cos \left(\delta+\Delta_{H}+\pi / 3\right)\right]}{X}
\end{array}\right.
$$



Fig. 8. Power control range (P.U.) with single-end hexagonal chopper (no back-to-back configuration) when $k_{0}$ and $k_{2}$ are equal to 0.5 .

C. Control Scheme for Hexagonal Chopper in SRF

Fig. 9 summarizes the generic control systems that can be used for both versions of the presented AC choppers (2-level hexagonal chopper and quasi-2-level mode M2AHC) when they are used to connect two AC networks (DG to utility or utility to utility). After the generation of voltage reference from central power flow controller, the hexagonal chopper performs as an AC-AC VSC and is dominated by voltage supporting controller (intermediate layer and inner current control layer). From (14), (15) and (16), direct axis output voltage can be controlled by DC component and direct component of $2^{\text {nd }}$ order signal in the modulating reference, while the quadrature axis voltage is only determined by $2^{\text {nd }}$ order quadrature signal.

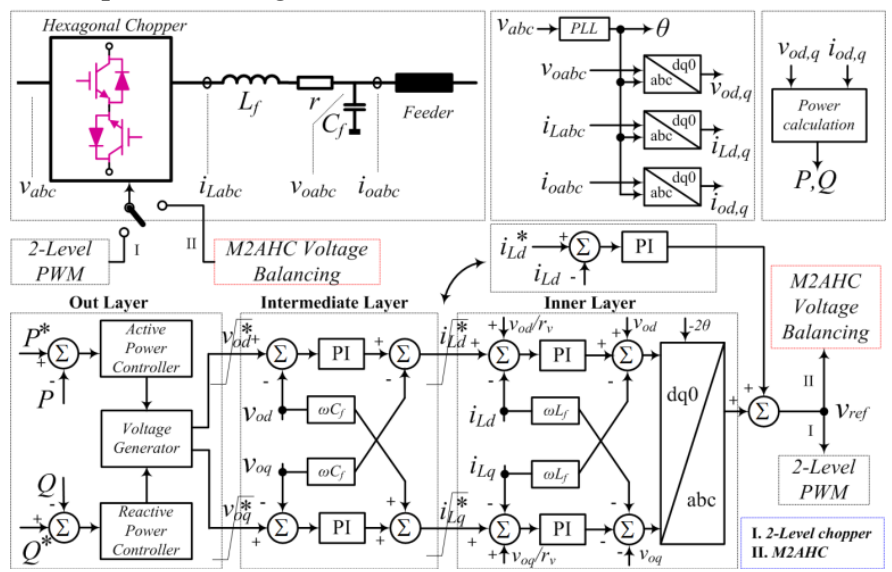

Fig. 9. Diagram of local controller for the hexagonal chopper.

The $d-q$ equations describing output voltage are shown in (22), based on which the intermediate voltage control layer are designed. Considering the terms $\left\{\lambda_{d}, \lambda_{q}\right\}$ defined in (23), which can be obtained from the proportional-integral (PI) controller as in (24). If $\left\{\rho_{p}, \rho_{i}\right\}$ are the PI parameters for $d$ - $q$ axes, the current reference for inner layer can be derived by (25) as in Fig. 9. The active damping factor $1 / r_{v}$ is employed for load adaption and oscillation suppression. From (22) - (25), the close loop voltage transfer function $G_{v o}$ is achieved in (26). 


$$
\begin{aligned}
& \left\{\frac{d v_{o d}}{d t}=\frac{i_{L d}+\omega C_{f} v_{o q}-i_{o d}}{C_{f}}\right. \\
& \frac{d v_{o q}}{d t}=\frac{i_{L q}-\omega C_{f} v_{o d}-i_{o q}}{C_{f}} \\
& \left\{\begin{array}{l}
\lambda_{d}=i_{L d}+\omega C_{f} v_{o q}-i_{o d} \\
\lambda_{q}=i_{L q}-\omega C_{f} v_{o d}-i_{o q}
\end{array}\right. \\
& \left\{\begin{array}{l}
\lambda_{d}=\rho_{p} \cdot\left(v_{o d}^{*}-v_{o d}\right)+\rho_{i} \cdot \int\left(v_{o d}^{*}-v_{o d}\right) d t \\
\lambda_{q}=\rho_{p} \cdot\left(v_{o q}^{*}-v_{o q}\right)+\rho_{i} \cdot \int\left(v_{o q}^{*}-v_{o q}\right) d t
\end{array}\right. \\
& \left\{\begin{array}{l}
i_{L d}^{*}=\lambda_{d}-\omega C_{f} v_{o q}+v_{o d} / r_{v} \\
i_{L q}^{*}=\lambda_{q}+\omega C_{f} v_{o d}+v_{o q} / r_{v}
\end{array}\right. \\
& G_{v o}=\frac{v_{o d}}{v_{o d}^{*}}=\frac{v_{o q}}{v_{o q}^{*}}=\frac{\rho_{i}+s \rho_{p}}{\rho_{i}+s\left(1 / r_{v}+\rho_{p}\right)+s^{2} C_{f}}
\end{aligned}
$$

Similarly, inner layer current controller is derived from (27), where $r$ is the resistance of filter inductor and $\left\{v_{\text {cond }}, v_{\text {conq }}\right\}$ is the converter output voltage before filter. By the same derivation as that in the intermediate control layer, the hexagonal chopper reference signal $\left\{v^{*}{ }_{\text {con.d. }}, v^{*}\right.$ con.q $\}$ and close loop inductor current transfer function $G_{i L}$ can be interpreted by (28) and (29) respectively, where $\left\{\sigma_{p}, \sigma_{i}\right\}$ are the PI parameters for current controller and $\left\{\chi_{d}, \chi_{q}\right\}$ are the PI controller output.

$$
\begin{aligned}
& \left\{\frac{d i_{L d}}{d t}=-\frac{r}{L_{f}} i_{L d}+\frac{v_{c o n . d}-v_{o d}+\omega L_{f} i_{L q}}{L_{f}}\right. \\
& \frac{d i_{L q}}{d t}=-\frac{r}{L_{f}} i_{L q}+\frac{v_{c o n . q}-v_{o q}-\omega L_{f} i_{L d}}{L_{f}} \\
& \left\{\begin{array}{l}
v_{\text {con.d }}^{*}=\chi_{d}-\omega L_{f} i_{L q}+v_{o d} \\
v_{\text {con. } q}^{*}=\chi_{q}+\omega L_{f} i_{L d}+v_{o q}
\end{array}\right. \\
& G_{i L}=\frac{i_{L d}}{i_{L d}^{*}}=\frac{i_{L q}}{i_{L q}^{*}}=\frac{\sigma_{i}+s \sigma_{p}}{\sigma_{i}+s\left(r+\sigma_{p}\right)+s^{2} L_{f}}
\end{aligned}
$$

According to (14) and (16), the signals $\left\{v_{\text {con.d }}^{*} v_{\text {con.q }}^{*}\right\}$ are transformed to $\left\{v_{\text {con.d. }}^{*},-v_{\text {con.q }}^{*}\right\}$ and sent to inverse park transformation with $-2 \theta(\theta$ is from fundamental phase locked loop, PLL for input voltage) rotational speed. The resulted modulating signal is in $2^{\text {nd }}$ order negative sequence.

Since the direct axis voltage can also be regulated by the DC component of the duty cycle, additional parallel loop using PI controller is inserted to further compensate the direct voltage output. It locates in inner control layer and shares the current reference with the previous current controller. This controller actually determines the DC modulating signal. Practically, this loop is set to be much slower than the $2^{\text {nd }}$ order harmonic modulation loops. The sum of the DC component and $2^{\text {nd }}$ order signal makes the final reference for the chopper system.

Based on above system control strategy, the final reference signal $v_{\text {ref }}$ is achieved. For typical 2-level hexagonal chopper, $v_{\text {ref }}$ is directly transferred to PWM module to generate the gate signals; while for M2AHC, $v_{\text {ref }}$ is used as the reference for cell capacitor voltage balancing scheme (Fig. 6).

\section{Discrete Drive to Remove DeAD-BAND EFFECT}

In previous sections, integrated drive scheme (two IGBTs are triggered by the same signal) for bidirectional switches is assumed to make the system performance easy to be accepted. Practically, dead-band time will cause cumbrous voltage spikes for 2-level hexagonal chopper and the M2AHC with integrated drive when both switches are turned off. Generally, in all direct AC-AC applications with integrated controlled bidirectional switches, dead-band time will cut off all paths for current flow at certain instance, leading to high voltage stresses on IGBTs. This issue is not covered by previous papers on direct AC-AC conversion using bidirectional switches $[15,16]$.

To fix this issue without adding any snubber, the integrated drive scheme should be modified but without influence to the conclusions in above sections. In Fig. 10, different modes of the employed bidirectional switch are displayed if the gate signals of two IGBTs are separately exerted. Fig. 10(a) shows the integrated drive situation where bidirectional reverse voltage blocking ability is addressed; Fig. 10(b) represents the reverse current blocked state when $G_{l}$ is always off; while in Fig. 10(c), bidirectional switch is derived back to single IGBT if $G_{l}$ is turned on constantly.

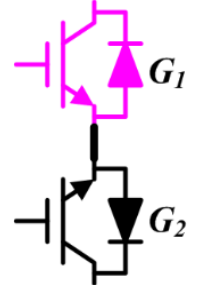

(a)

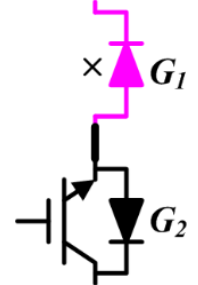

(b)

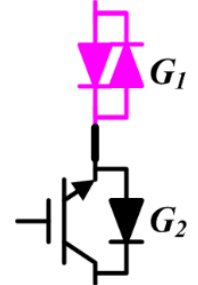

(c)
Fig. 10. Bidirectional switch with two series IGBTs: (a) integrated drive; (b) reverse-blocking state; (c) reverse conduction state.

It is straightforward that a discrete drive scheme with a loose reverse blocking ability should be considered to remove the dead-band effect. In fact, the two IGBTs will sustain the reverse voltage alternatively due to the polarity of the input voltage. Accordingly, with different polarities of input voltage, one IGBT in each switch unit can be kept in conduction state as Fig. 10(c) to supply extra path for the current during deadband time, thus eliminating the voltage spikes. Actually, with this idea, the presented converter can be decoupled into two chopper units with unidirectional switches shown by Fig. 11.

Notice that the discrete drive scheme will not change the system performance of the AC chopper. For 2-level converter, an input voltage transducer should be added. However, in M2AHC, since cell capacitor voltages are necessarily sampled for voltage balancing, voltage polarity can be decided by the average voltage of cell capacitors. In this way, no extra voltage transducer is needed. Additionally, the total switching times of the power switches can be nearly halved by the discrete drive scheme (switching losses are reduced slightly because the unblocked IGBT in integrated drive will always experience zero voltage switching - ZVS). 


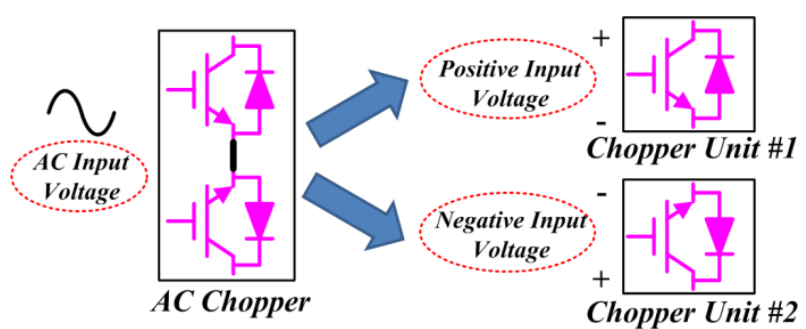

Fig. 11. Decoupling principle of AC chopper system by using discrete drive scheme for bidirectional switches.

\section{Simulation AND EXPERIMENTAL RESUlts}

To verify the operation principle and voltage balancing scheme for M2AHC, simulation on a three-phase 5-level (four cells per arm) model and experimental work on a single-phase 3-level test rig have been carried out respectively.

In further, heterodyne control scheme (system level) for the proposed hexagonal chopper system is verified by experiment work on a three-phase real-2-level mode prototype.

\section{A. Simulation Tests}

In this part, a illustrative four-cell version (five-level during transition) of the presented M2AHC has been established in Matlab/Simulink with following specifications: input line voltage: $10 \mathrm{kV}$ (RMS); input $C$-filter: $10 \mu \mathrm{F}$, cell capacitor: $10 \mu \mathrm{F}$, arm inductor: $10 \mu \mathrm{H}$, switching frequency: $2.5 \mathrm{kHz}$, output filter inductor: $15 \mathrm{mH}$, output filter capacitor: $100 \mu F$, active power load: $5.4 M W$, reactive power load: 2.1MVar. A composite modulating signal with $k_{0}=0.5$, $k_{2}=0.12, \varphi=25^{\circ}$ and $10 \mu s$ step duration for quasi-2-level mode are exerted on this model.

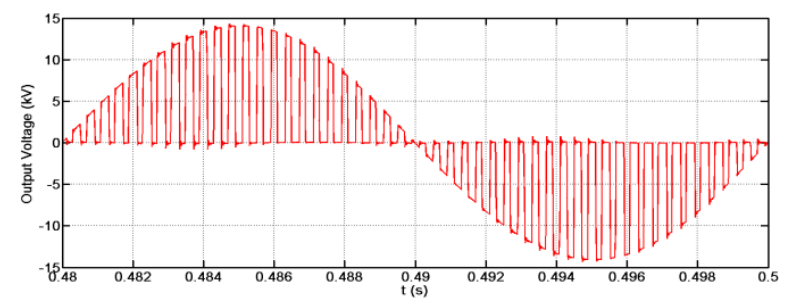

(a)
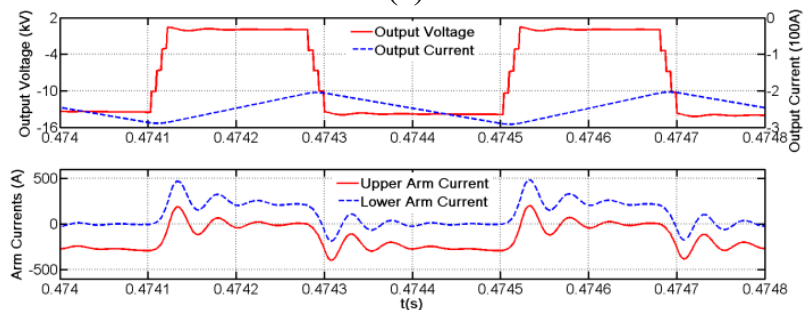

(b)

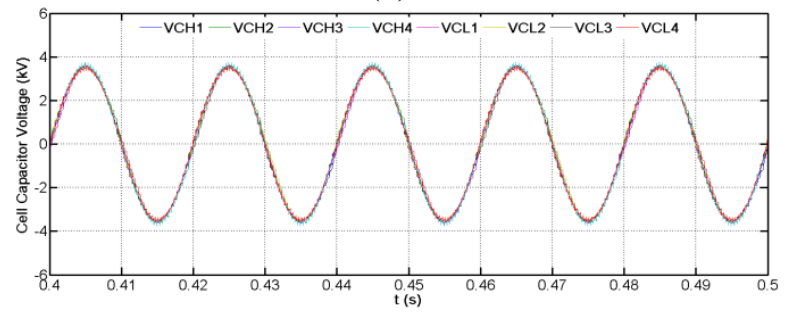

(c)

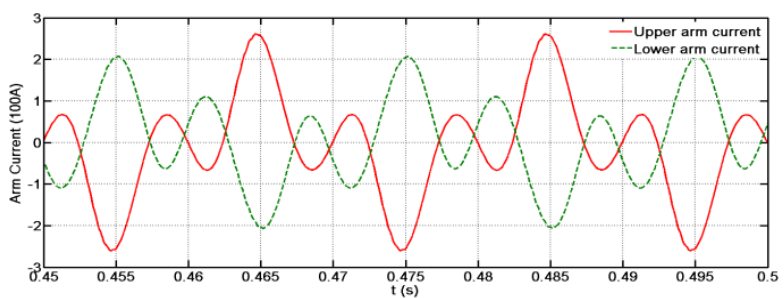

(d)

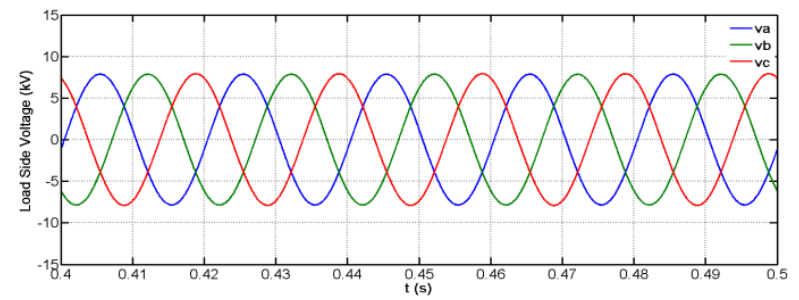

(e)

Fig. 12. Simulation results: (a).chopped output voltage for one phase; (b).quasi-2-level mode with 5-step voltage transition and output/arm currents; (c).voltage balancing results; (d).upper and lower arm currents after moving average filter; (e).three-phase output voltage.

The output voltage waveform in Fig. 12(a) shows that the presented M2AHC operates in chopper mode with duty cycle as control input. Microscopic version of the output voltage together with the output current and arm currents are displayed in in Fig. 12(b). Observe that the use of quasi-two-level operation introduces intermediate voltage steps to avoid high voltage level switching. Thus, reduces $d v / d t$ may be impressed on the loads connected to the output. Additionally, Fig. 12(b) shows that the M2AHC in quasi-2-level mode simultaneously conduct the load current through the upper and lower arms only during transitions of the output phase via artificially induced intermediate voltage levels; otherwise, the entire load current is conducted either through upper or lower arm. In Fig. 12(c), the input voltage is equally shared by the eight cell capacitors, verifying the feasibility of the voltage balancing strategy discussed previously. Notice that small AC capacitors based on (8) are sufficient for the proposed ratings (10kV and $6 M V A)$. Fig. 12(d) displays the moving averaged upper and lower arm currents which contain fundamental and $3^{\text {rd }}$ order harmonics as in section III. Recall (17) that fundamental currents of two arms are not necessarily equal. High quality post-filter three-phase output voltage of the M2AHC is demonstrated in Fig. 12(e).

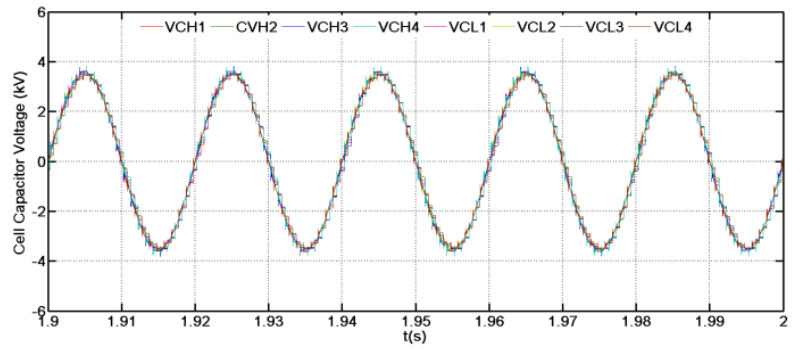

Fig. 13. Voltage balancing results for zero power factor condition.

The voltage balancing results are further examined by Fig. 13 under the zero power factor condition, which is the most challenging situation for modular multilevel based converters (such as conventional MMC). It is observed that the cell capacitor voltages remain stable and balance. Therefore, the 
proposed $\mathrm{M} 2 \mathrm{AHC}$ is verified to be able to survive under arbitrary power factor condition, provided the Fig. 12(d) and Fig. 13 represent the two extreme conditions (nearly unity and zero power factors).

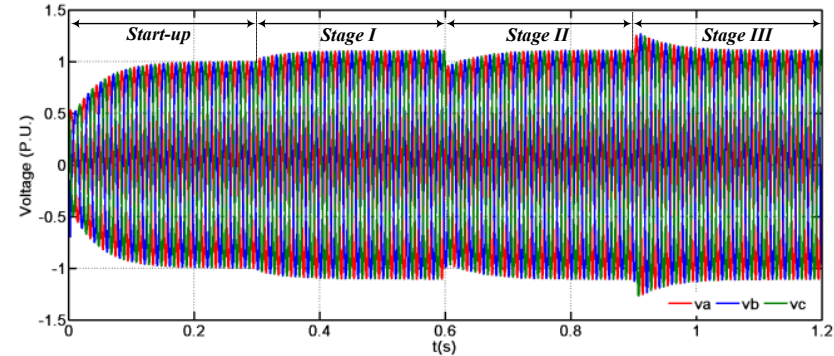

(a)

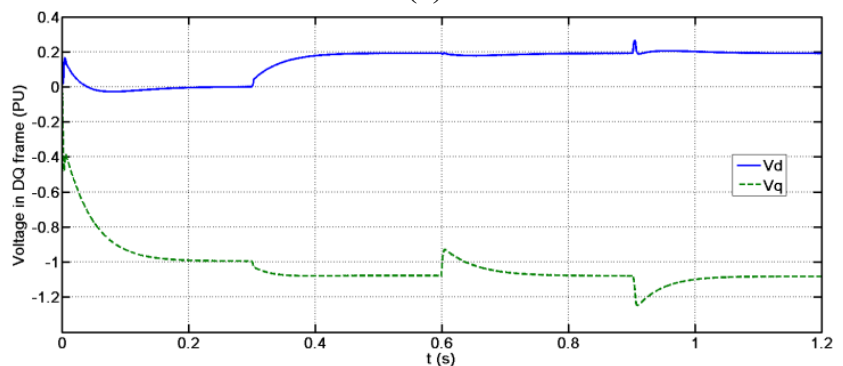

(b)

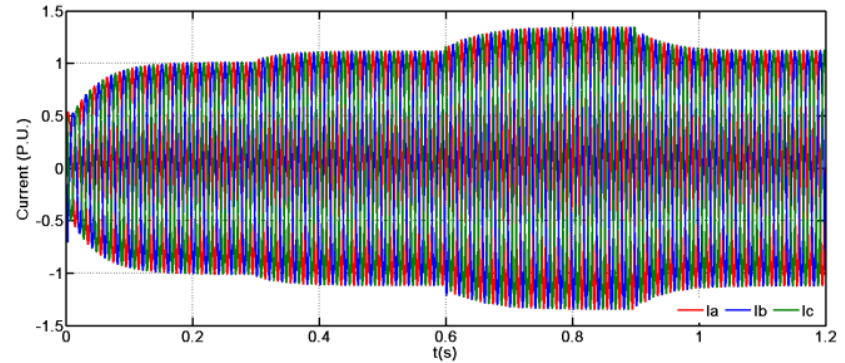

(c)

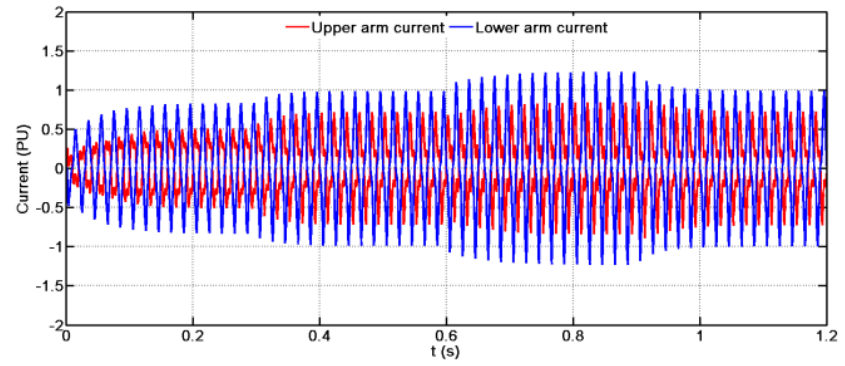

(d)

Fig. 14. Voltage command and power load transient processes for the proposed hexagonal chopper working under voltage supporting mode: (a) output voltage in time domain; (b) output voltage in SRF; (c) load current; (d) moving-averaged arm current for one phase.

In order to evaluate the transient process, the post-filter voltage of the above model is examined under step changes. In Fig. 14, during $0-0.3 \mathrm{~s}$, the voltage is established to be $1 \mathrm{pu}$; then the voltage control command is shifted to $1.1 \mathrm{pu}$ with a positive $10^{\circ}$ phase shift at $0.3 \mathrm{~s}$; the load power is step increased to $1.2 \mathrm{pu}$ and recovered to $1 \mathrm{pu}$ at $0.6 \mathrm{~s}$ and $0.9 \mathrm{~s}$ respectively. Fig. 14(a) and (b) show the waveforms of the output voltage in time domain and SRF during these transient processes. Fig. 14(c) and (d) represent the load current and moving-averaged arm current (the two arm currents are not necessarily equal according to (17)). By these results, the effectiveness of the control strategy in Fig. 9 is proven. It is also noticed that the cell capacitor voltage will remain as Fig. 12(d) (or Fig. 13) during transient processes because the sum of the cell capacitor voltage for one arm is always equal to the input voltage and each cell capacitor voltage is uniformly distributed due to the voltage balancing strategy.

Based on the theoretical discussions in section II and above results, it is concluded that the $\mathrm{M} 2 \mathrm{AHC}$ performs similarly as typical two-level AC chopper, except for the employment of half-bridge cells enabling the generation of a step voltage transition between zero and instantaneous peaks (positive or negative). The adopted voltage balancing strategy is able to ensure the uniform distribution of the input voltage across the cell capacitors, thus avoiding the need of series device connection in medium and high voltage applications.

B. Experimental Results

1) Modulation and Voltage Balancing for $M 2 A H C$

Based on the simulation above, the voltage balancing scheme and open loop performance of $\mathrm{M} 2 \mathrm{AHC}$ is further verified on a single-phase prototype with two cells per arm as in Fig. 15. The Infineon TriCore $1796 \mathrm{~B}$ is employed as the controller for this part. The specifications are as follows: input voltage: $240 \mathrm{~V}$ (RMS value), IGBT: FGA20S120M $(1.2 \mathrm{kV}$, $20 \mathrm{~A}$ ), switching frequency: $2.5 \mathrm{kHz}$, power rating: $1.2 \mathrm{kVA}$, input $C$-filter: $10 \mu F$, cell capacitor: $10 \mu F$, output filter inductor: $10 \mathrm{mH}$, output filter capacitor: $100 \mu \mathrm{F}$, load condition: $10 \mathrm{mH}$ and $10 \Omega$ in series.



Fig. 15. Photo of the experiment setup for single-phase M2AHC with two cells per arm.

Fig. 16(a) shows the effective gate signals for lower switches in each cell. It can be concluded that the upper arm and lower arm mainly work in complementary (chopper) and small durations on the edges are employed for quasi-2-level mode transition. Accordingly, the generated output voltage with intermediate step and the arm currents are displayed in Fig. 16(b), where it can be seen the arm currents are discontinuous for the proposed $\mathrm{M} 2 \mathrm{AHC}$ and quasi-2-level operation can slow the voltage rising or falling rate on the chopped edge. Fig. 16(c) and (d) are the fundamental period time based waveforms of output voltage and arm currents respectively. The voltage balancing strategy developed in section II for M2AHC is verified by Fig. 16(e) since the four cell capacitor voltage waveforms coincide with each other.

\section{2) System Control with Heterodyne Method}

In order to verify the system control scheme developed in section III part C, a real-2-level hexagonal chopper has been built and tested. The photo for the experiment setup is presented in Fig. 17. The input bus and output bus are interfaced by two three-phase transformers with all reference 
terminals accessible for voltage adaption. The TI DSP TMS320F28335 is employed as the controller. Specifications of the tested prototype are: grid voltage: $110 \mathrm{~V}$ (line-to-line RMS value, three-phase), IGBT: FGA20S120M (1.2kV, 20A), switching frequency: $2.5 \mathrm{kHz}$, power rating: $1.2 \mathrm{kVA}$, input filter capacitor: $10 \mu F$, output filtering inductor: $10 \mathrm{mH}$, output filter capacitor: $100 \mu F$.



(a)

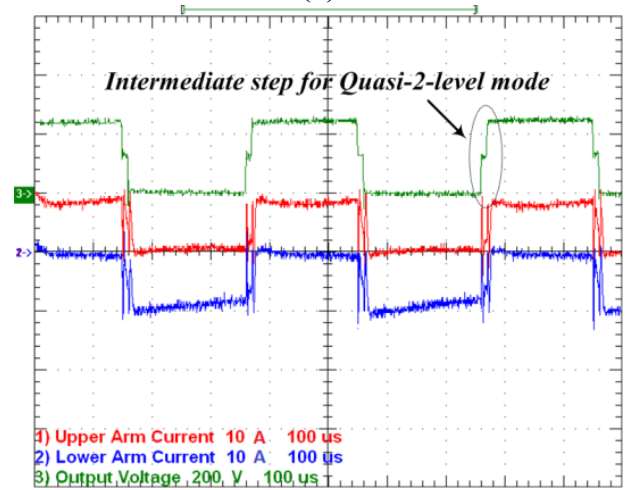

(b)

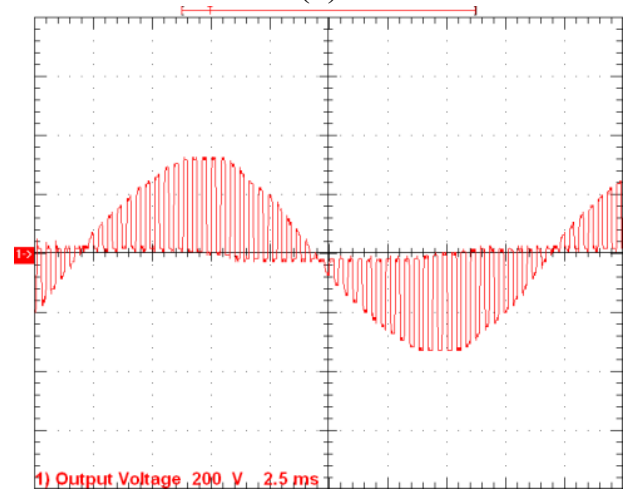

(c)

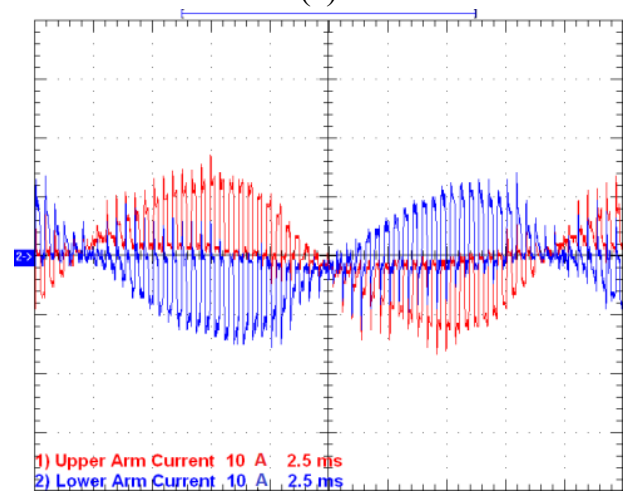

(d)

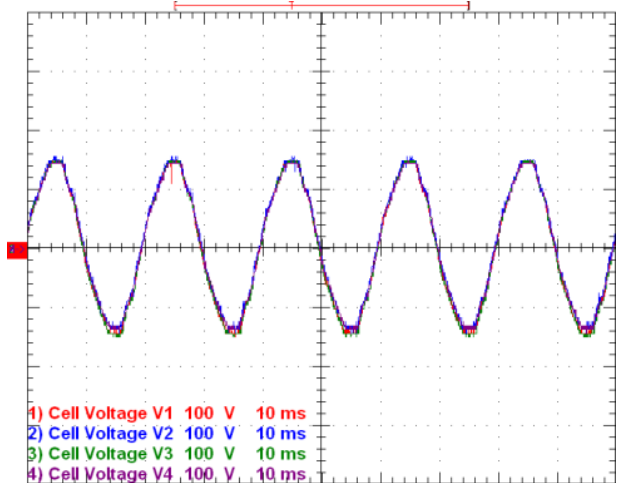

(e)

Fig. 16. Test results for single-phase M2AHC with 2 cells per arm: (a) effective gate signals for lower switches in 4 cells; (b) interaction between output voltage (with intermediate step) and arm currents under switching period time base; (c) output voltage under fundamental period time base; (d) arm currents under fundamental period time base; (e) cell capacitor voltage balancing results.

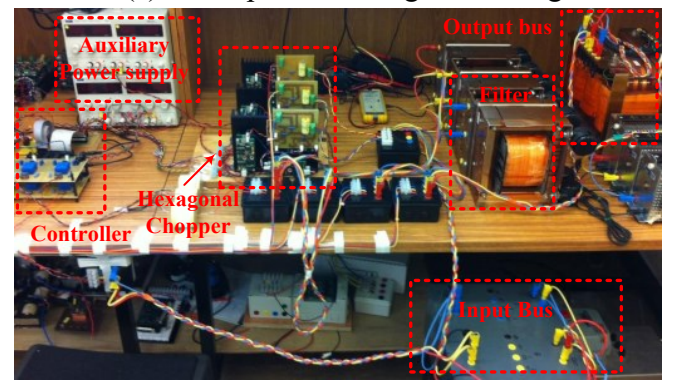

Fig. 17. Photo of the experiment setup for hexagonal chopper system.



(a)

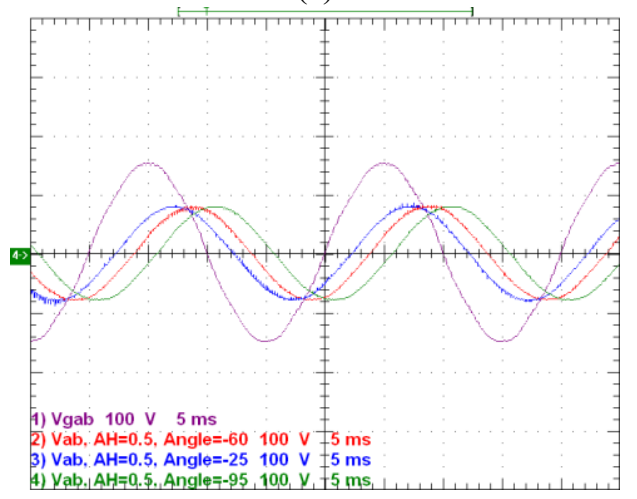

(b)

Fig. 18. Comparison of voltage synthesis ability for the hexagonal chopper: (a) constant duty cycle; (b) heterodyne method.

At first, the voltage synthesis ability of hexagonal chopper is demonstrated by a standalone mode test, where heterodyne modulation and conventional constant duty cycle methods are 
employed respectively. In Fig. 18(a), output voltage phaseshift causes amplitude changes simultaneously when duty cycle is constant. This is because the output voltage always falls in the envelope formed by three-phase input voltage. In Fig. 18(b), with heterodyne modulation, the amplitude can be controlled constantly independent of phase-shift as described mathematically by (15), (16) and (19). When heterodyne method is used, $3^{\text {rd }}$ order current will circulate in the hexagonal ring as discussed previously, which can be verified by Fig. 19 (notice that this waveform is not discontinuous because the current of the delta connected input $C$-filter is also included). Recall (17) and (18), the fundamental currents in upper and lower arms are in opposite direction with different amplitude; while $3^{\text {rd }}$ order components are equal to each other, facilitating the trap ability for zero-sequence current.

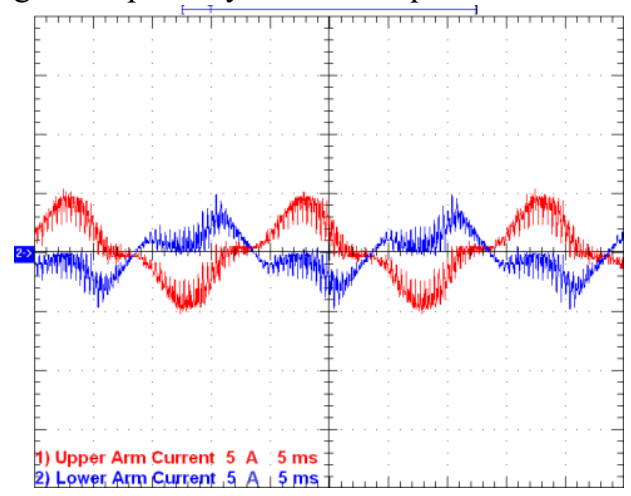

Fig. 19. Arm currents (plus the input C-filter current) under heterodyne modulation $\left(A_{H}=0.5, \Delta H=-25^{\circ}\right)$.

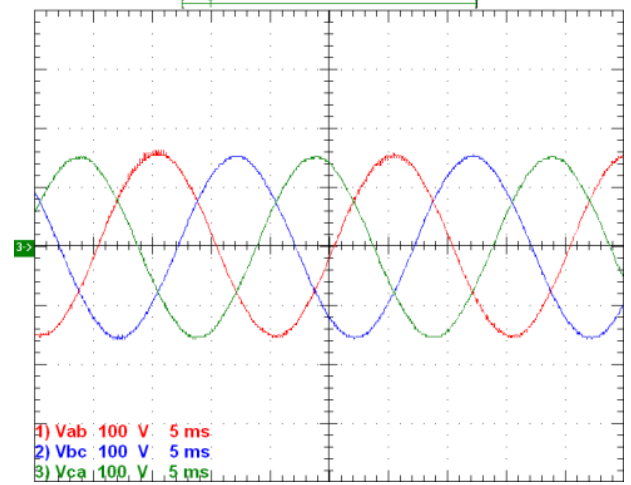

Fig. 20. Three-phase output voltage on transformer terminal with zero power flow.

To further verify the heterodyne control strategy, the tested chopper is feed from the grid and its output is also connected back to the grid through a 1:2 transformer with $60^{\circ}$ phase leading. Since the power controller that can slightly refine the voltage reference is not considered in this paper, $3 \Omega$ resistor and $3 \mathrm{mH}$ inductor are inserted as the line impedance when the voltage reference is manually changed (with large amplitude and phase errors). Fig. 20 shows the zero plow flow situation, where the three-phase output bus voltage is exactly the same with grid voltage. In Fig. $21, A_{H}$ is set to be 0.4 . The power flow control results when output bus voltage phase is $10^{\circ}$ leading and $10^{\circ}$ lagging to the grid are demonstrated respectively. Similarly, if the output voltage gain is controlled as $0.6, \pm 10^{\circ}$ phase error can still be regulated by the proposed hexagonal chopper system, and the corresponding power flow control results are illustrated by Fig. 22. These results have verified the decoupled and extended voltage synthesis range (on both phase-shift and amplitude) by the heterodyne modulation in Fig. 7.

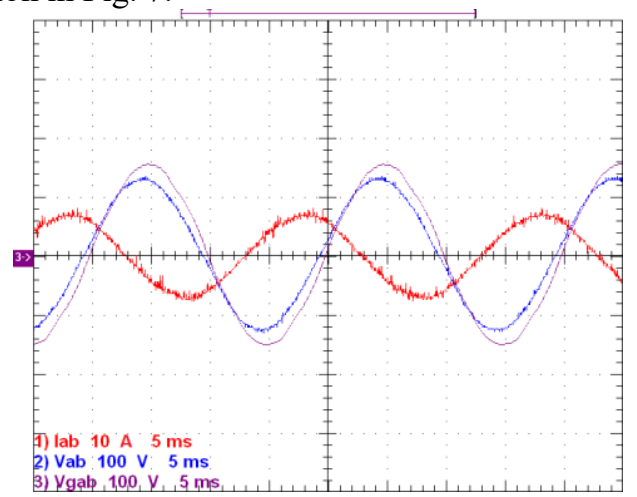

(a)

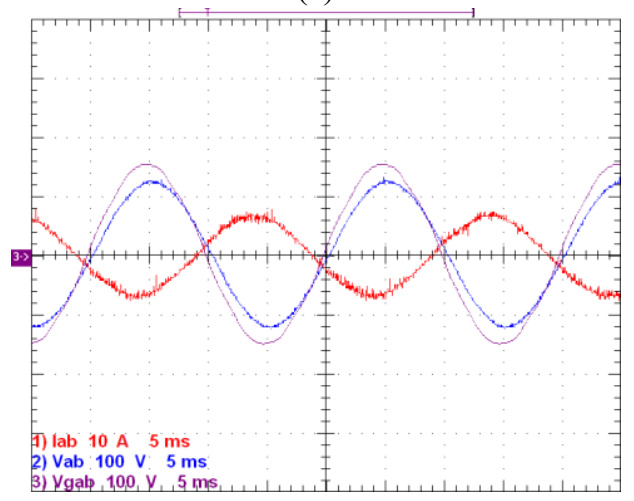

(b)

Fig. 21. Power flow control with hexagonal chopper system: (a) $A_{H}=0.4, \delta=10^{\circ}$; (b) $A_{H}=0.4, \delta=-10^{\circ}$.

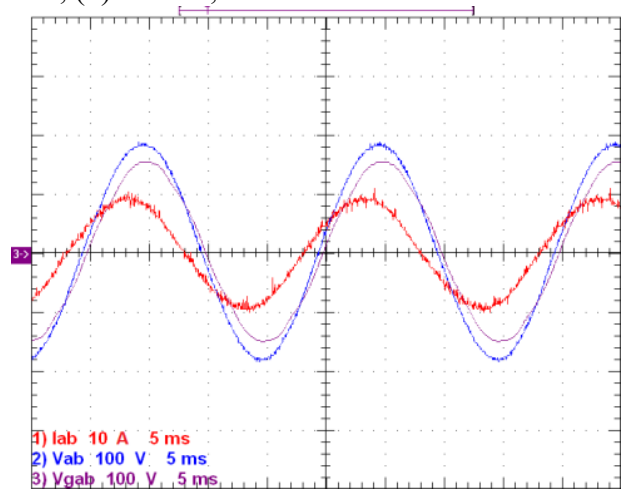

(a)

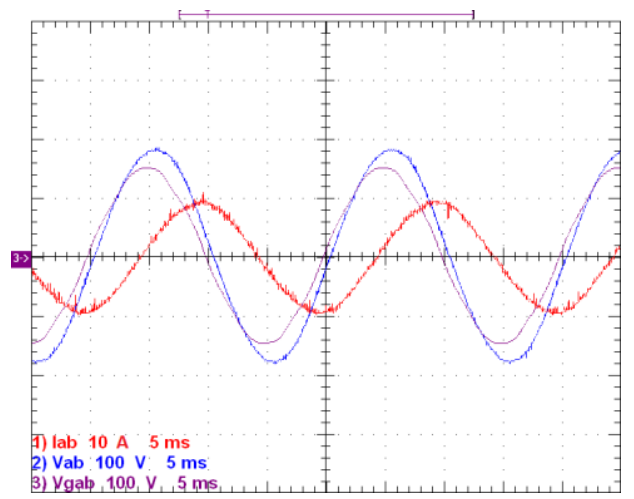

(b)

Fig. 22. Power flow control with hexagonal chopper system: (a) $A_{H}=0.6, \delta=10^{\circ}$; (b) $A_{H}=0.6, \delta=-10^{\circ}$. 


\section{CONCLUSIONS}

This paper has proposed two versions of three-phase hexagonal chopper system dedicated to the enhancement of power flow control for AC power networks. The first version of the hexagonal chopper consists of six bidirectional switches connected end to end without energy storage components. For scalability in high voltage applications, the second version known as modular multilevel AC hexagonal chopper (M2AHC) is developed. Operational principle, modulation and control of both versions are described in detail and substantiated using simulations and experimentations. The key contributions of this paper are summarized as follows:

- The hexagonal chopper achieves direct AC-AC conversion with small footprint, reduced switch count and control complexity compared to matrix converter, which makes it attractive as power flow controller between AC networks. However, direct AC-AC converters are not suggested as interfacing for wind turbine for lacking of side-to-side decouple.

- The proposed M2AHC employs significant smaller AC cell capacitor and arm inductors compared to Hexverter, where large DC capacitors and arm inductors are used.

- In high voltage applications, quasi-2-level operation for $\mathrm{M} 2 \mathrm{AHC}$ divides the voltage level transition into small multi-steps without significant compromise on maximum output voltage, slowing the voltage transition rate $(d v / d t)$. Besides, the redundant switching states can be assigned for voltage balancing.

- Heterodyne modulation with insertion of $2^{\text {nd }}$ order negative sequence component has been used to decouple the phase and amplitude regulation. It also extends the power flow control range.

- Heterodyne modulation requires $3^{\text {rd }}$ order zero sequence current to flow in the power path. Since the proposed converters are delta connected, this current can be trapped in the inner hexagonal ring which will not influence the line current. If star configuration is employed, neutral line must be used to supply the path to circulate the $3^{\text {rd }}$ order current. Otherwise, the input filter is going to resonant.

Back-to-back configuration of the hexagonal chopper or $\mathrm{M} 2 \mathrm{AHC}$ can be formed at the PCC (point of common coupling) to adapt the voltage and double the control flexibility when each $\mathrm{AC}$ grid is equipped in the terminal with the proposed converter.

\section{REFERENCES}

[1] R. Majumder, A. Ghosh, G. Ledwich, and F. Zare, "Power Management and Power Flow Control With Back-to-Back Converters in a Utility Connected Microgrid," Power Systems, IEEE Transactions on, vol. 25, pp. 821-834, 2010.

[2] C. Changhee, J. Jin-Hong, K. Jong-Yul, K. Soonman, P. Kyongyop, and K. Sungshin, "Active Synchronizing Control of a Microgrid," Power Electronics, IEEE Transactions on, vol. 26, pp. 3707-3719, 2011

[3] Y. Xunwei, S. Xu, N. Xijun, and A. Q. Huang, "System Integration and Hierarchical Power Management Strategy for a Solid-State Transformer Interfaced Microgrid System," Power Electronics, IEEE Transactions on, vol. 29, pp. 4414-4425, 2014.
[4] M. A. Zamani, T. S. Sidhu, and A. Yazdani, "Investigations Into the Control and Protection of an Existing Distribution Network to Operate as a Microgrid: A Case Study," Industrial Electronics, IEEE Transactions on, vol. 61, pp. 1904-1915, 2014.

[5] P. C. Loh, L. Ding, C. Yi Kang, and F. Blaabjerg, "Autonomous Operation of Hybrid Microgrid With AC and DC Subgrids," Power Electronics, IEEE Transactions on, vol. 28, pp. 2214-2223, 2013.

[6] C. N. Rowe, T. J. Summers, R. E. Betz, D. J. Cornforth, and T. G. Moore, "Arctan Power - Frequency Droop for Improved Microgrid Stability," Power Electronics, IEEE Transactions on, vol. 28, pp. 3747-3759, 2013.

[7] I. U. Nutkani, L. Poh Chiang, and F. Blaabjerg, "Droop Scheme With Consideration of Operating Costs," Power Electronics, IEEE Transactions on, vol. 29, pp. 1047-1052, 2014.

[8] C. T. Lee, C. C. Chu, and P. T. Cheng, "A New Droop Control Method for the Autonomous Operation of Distributed Energy Resource Interface Converters," Power Electronics, IEEE Transactions on, vol. 28, pp. 1980-1993, 2013.

[9] A. Ecklebe, A. Lindemann, and S. Schulz, "Bidirectional Switch Commutation for a Matrix Converter Supplying a Series Resonant Load," Power Electronics, IEEE Transactions on, vol. 24, pp. 11731181, 2009.

[10] B. Metidji, N. Taib, L. Baghli, T. Rekioua, and S. Bacha, "Novel Single Current Sensor Topology for Venturini Controlled Direct Matrix Converters," Power Electronics, IEEE Transactions on, vol. 28, pp. 3509-3516, 2013.

[11] S. Yao, S. Mei, L. Xing, W. Hui, and G. Weihua, "A General Constructive Approach to Matrix Converter Stabilization," Power Electronics, IEEE Transactions on, vol. 28, pp. 418-431, 2013.

[12] F. Mancilla-David, "AC link Vector Switching Converters for power flow control and power quality: A review," in North American Power Symposium (NAPS), 2009, 2009, pp. 1-7.

[13] J. Kaniewski, Z. Fedyczak, and G. Benysek, "AC Voltage Sag/Swell Compensator Based on Three-Phase Hybrid Transformer With BuckBoost Matrix-Reactance Chopper," Industrial Electronics, IEEE Transactions on, vol. 61, pp. 3835-3846, 2014.

[14] L. A. C. Lopes, G. Joos, and O. Boon-Teck, "A high power PWM quadrature booster phase-shifter based on a multi-module converter," in Power Electronics Specialists Conference, 1995. PESC '95 Record., 26th Annual IEEE, 1995, pp. 375-380 vol.1.

[15] D. M. Divan, D. M. Divan, and J. Sastry, "Voltage Synthesis Using Dual Virtual Quadrature Sources - A New Concept in AC Power Conversion," Power Electronics, IEEE Transactions on, vol. 23, pp. 3004-3013, 2008.

[16] Z. Youjun and R. Xinbo, "AC-AC Converter With Controllable Phase and Amplitude," Power Electronics, IEEE Transactions on, vol. 29, pp. 6235-6244, 2014.

[17] L. Baruschka and A. Mertens, "A New Three-Phase AC/AC Modular Multilevel Converter With Six Branches in Hexagonal Configuration," Industry Applications, IEEE Transactions on, vol. 49, pp. 1400-1410, 2013.

[18] I. A. Gowaid, G. P. Adam, A. M. Massoud, S. Ahmed, D. Holliday, and B. W. Williams, "Quasi Two-Level Operation of Modular Multilevel Converter for Use in a High-Power DC Transformer With DC Fault Isolation Capability," Power Electronics, IEEE Transactions on, vol. 30, pp. 108-123, 2015.

[19] M. A. Perez, J. Rodriguez, E. J. Fuentes, and F. Kammerer, "Predictive Control of AC-AC Modular Multilevel Converters," Industrial Electronics, IEEE Transactions on, vol. 59, pp. 2832-2839, 2012.

[20] W. Weimin, H. Yuanbin, and F. Blaabjerg, "An LLCL Power Filter for Single-Phase Grid-Tied Inverter," Power Electronics, IEEE Transactions on, vol. 27, pp. 782-789, 2012.

[21] G. P. Adam, O. Anaya-Lara, G. M. Burt, D. Telford, B. W. Williams, and J. R. McDonald, "Modular multilevel inverter: Pulse width modulation and capacitor balancing technique," Power Electronics, IET, vol. 3, pp. 702-715, 2010.

[22] V. S. P. Cheung, H. S. H. Chung, W. Ke-Wei, and A. W. L. Lo, "Paralleling Multiple Static Synchronous Series Compensators Using Daisy-Chained Transformers," Power Electronics, IEEE Transactions on, vol. 29, pp. 2764-2773, 2014.

[23] W. Huai, H. S. H. Chung, and L. Wenchao, "Use of a Series Voltage Compensator for Reduction of the DC-Link Capacitance in a Capacitor-Supported System," Power Electronics, IEEE Transactions on, vol. 29, pp. 1163-1175, 2014. 


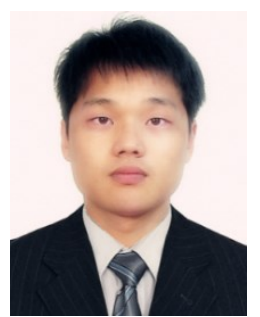

Peng Li received the B.Sc. and M.Sc. degree in Applied Power Electronics and Electrical Engineering from Zhejiang University, Hangzhou, China, in 2009 and 2012, respectively. He is currently pursuing the $\mathrm{Ph} . \mathrm{D}$. degree in Department of Electronics and Electrical Engineering, University of Strathclyde, Glasgow, UK.

His research interests include the applied power electronics in $\mathrm{AC}$ and $\mathrm{DC}$ power networks.

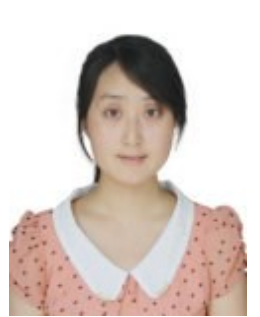

Yachao Wang received the B.Sc. degree in Department of Electrical Engineering, Xi'an Jiaotong University, Xi'an, China, in 2009, and M.Sc. degree in Applied Power Electronics, Zhejiang University, Hangzhou, China, in 2012, respectively.

She is now with State Grid Corporation of China. Her research interests include high efficiency power electronics converters and the utility applications.

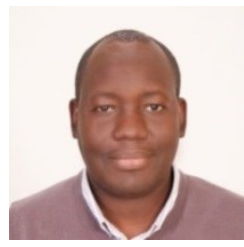

G.P. Adam (M' 12) received a first class BSc and MSc from Sudan University for Science and Technology, Sudan in 1998 and 2002 respectively; and. a PhD in Power Electronics from University of Strathclyde in 2007. He has been working as a research fellow with Institute of Energy and Environment, University of Strathclyde in Glasgow, UK, since 2008. His research interests are fault tolerant voltage source converters for HVDC systems; control of HVDC transmission systems and multi-terminal HVDC networks; voltage source converter based FACTS devices; and grid integration issues of renewable energies. Dr Adam has authored and co-authored several technical reports, and journal and conference papers in the area of multilevel converters and HVDC systems, and grid integration of renewable power. Also, he is actively contributing to reviewing process for several IEEE and IET Transactions and Journals, and conferences. Dr Adam is an active member of IEEE and IEEE Power Electronics Society.

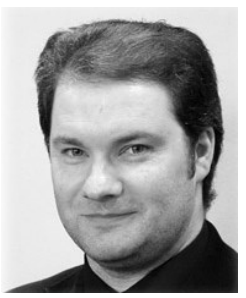

Derrick Holliday has research interests in the areas of power electronics, electrical machines and drives. In 1995 he obtained the degree of $\mathrm{PhD}$ from Heriot Watt University and, since then, has held full-time academic posts at the Universities of Bristol and Strathclyde. He has authored or co-authored over 70 academic journal and conference publications. He is currently leading industrially funded research in the field of power electronics for HVDC applications, and is coinvestigator on research programmes in the fields of photovoltaic systems and the interface of renewable energy to HVDC systems.

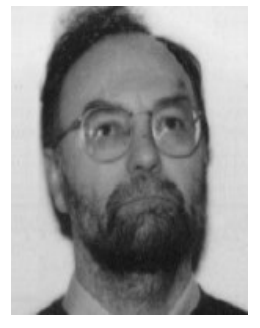

B.W. Williams received the M.Eng.Sc. degree from the University of Adelaide, Australia, in 1978, and the $\mathrm{Ph} . \mathrm{D}$. degree from Cambridge University, Cambridge, U.K., in 1980. After seven years as a Lecturer at Imperial College, University of London, U.K., he was appointed to a Chair of Electrical Engineering at Heriot-Watt University, Edinburgh, U.K, in 1986. He is currently a Professor at Strathclyde University, UK. His teaching covers power electronics (in which he has a free internet text) and drive systems. His research activities include power semiconductor modelling and protection, converter topologies, soft switching techniques, and application of ASICs and microprocessors to industrial electronics. 